\section{Neck pain disguised as spondyloarthrosis}

\section{Ramos-Estebanez, J L Hernández, R Muñoz, H Alonso, I Abascal, F Trigueros, C Diez}

Answers on $p 122$.

A 70 year old man was referred to us complaining about neck pain that had irradiated to the left shoulder and clavicular region over 12 months. There was no history of external trauma, or exposure to radiation, and no other manifestations were apparent initially. A prominent cervical spondylosis that mildly diminished the spinal duct diameter had been monitored with regular radiographic examination. The pain had been treated by his family physician, with an initial good response, with nonsteroidal anti-inflammatory agents and physiotherapy.

One month later the patient had developed tingles on the left upper limb and had difficulty in combing his hair. He complained about weakness in standing up and climbing stairs. An increasingly clumsy gait was also reported. The neck pain was enhanced by cervical movements and coughing, and started to be unbearable after an 11 month period, thus he was referred to our centre.

Physical examination evidenced diminished bicipital and enhanced tricipital reflexes in the left arm at admission. Proximal weakness of the left upper limb $(2 / 5)$ was detected. Left lower extremity spasticity and an ataxic-spastic gait were also noted. The remainder of the neurological examination was completely normal. Nevertheless, the patient developed severe mictional urge, and tetraparesis with evident pyramidalism, mainly involving the left hemibody throughout the next three weeks. Neither amyotrophy nor fasciculations were observed.

Baseline laboratory investigations, including haematology, and serum biochemical and coagulation profile, were graphy confirmed spondyloarthrosis and a diminished height at intervertebral C5-C6 space (fig 1). A cervical magnetic resonance imaging (MRI) study was performed (fig 2).

\section{QUESTIONS}

(1) What is the differential diagnosis?

(2) What is the diagnosis?

(3) If compression of medullary structures is found, would it be of intramedullary or extramedullary nature?

(4) What is the treatment and prognosis of this condition?

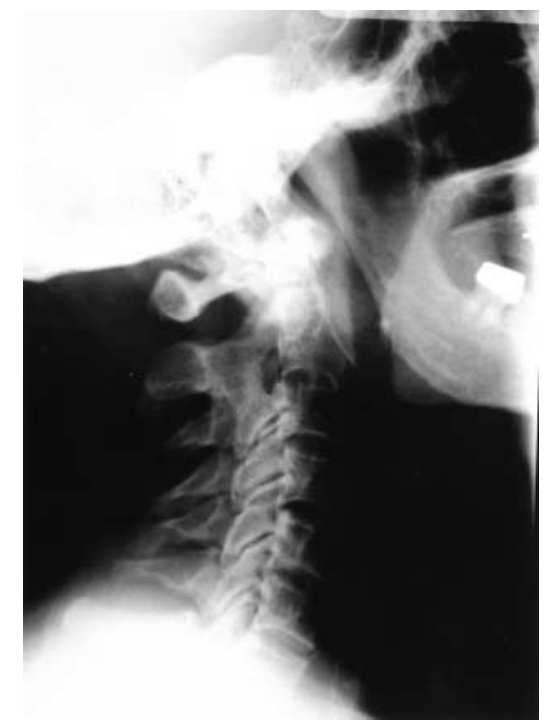

Figure 1 Lateral cervical radiograph. within normal limits. Cervical radio-

\section{Authors' affiliations \\ C Ramos-Estebanez, J L Hernández, H Alonso, I Abascal, Department of Internal Medicine, University Hospital Marques de Valdecilla, University of Cantabria, Santander, Spain \\ R Muñoz, Department of Neurology \\ F Trigueros, Department of Neurosurgery \\ C Diez, Department of Radiology}

Correspondence to: Dr José Luis Hernández, Department of Internal Medicine, University Hospital Marques de Valdecilla, 39008,

Santander, Spain; joselvishernandez@ono.com

Submitted 6 February 2002

Accepted 22 July 2002

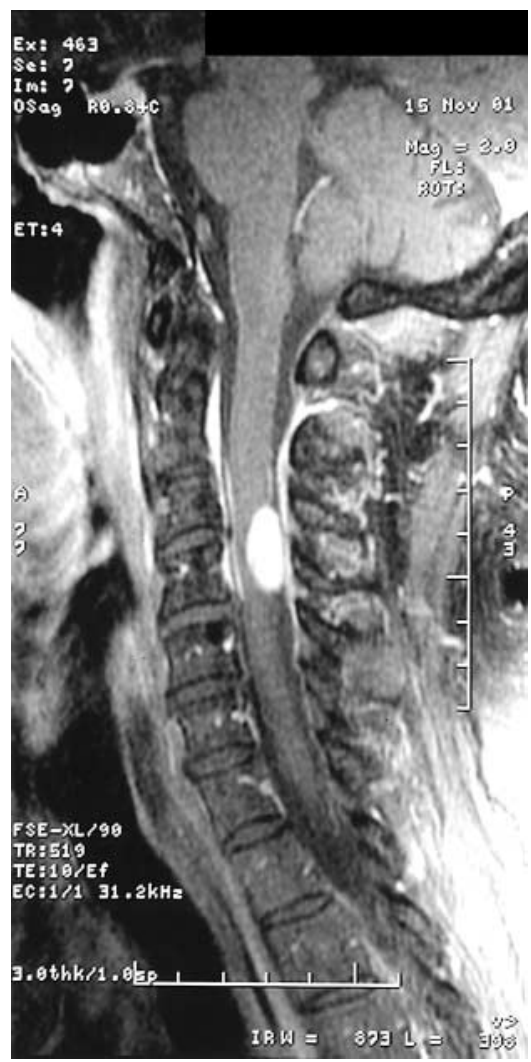

Figure 2 Magnetic resonance image. 